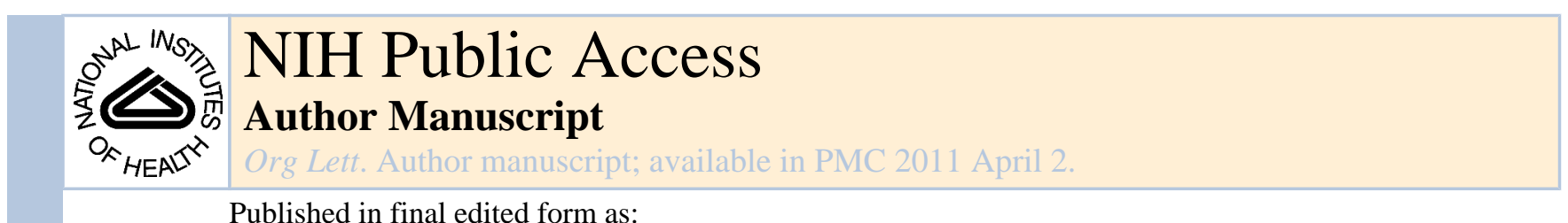

Published in final edited form as:

Org Lett. 2010 April 2; 12(7): 1524-1527. doi:10.1021/ol100249v.

\title{
Liposomal Circular Dichroism. Assignment of Remote Stereocenters in Plakinic Acids K and L from a Plakortis - Xestospongia Sponge Association
}

\author{
Doralyn S. Dalisay $§, \ddagger, \operatorname{Tim}$ Quach $\S$, and Tadeusz F. Molinski $§, \dagger,{ }^{\star}$
}

Department of Chemistry and Biochemistry, and Skaggs School of Pharmacy and Pharmaceutical Sciences, University of California, San Diego, 9500 Gilman Drive, La Jolla, California 92093

\begin{abstract}
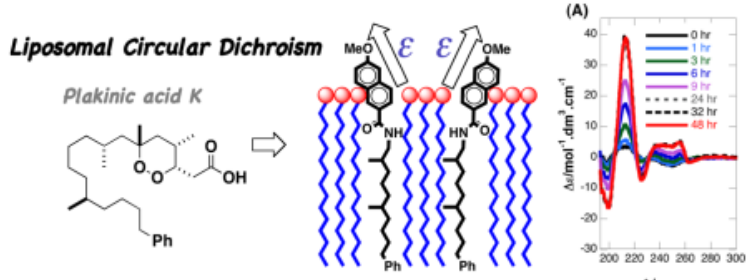

Wnm

Two new $\omega$-phenyl polyketide peroxides, plakinic acids $\mathrm{K}$ and $\mathrm{L}$, were isolated from a two-sponge association of Plakortis halichondroides and Xestospongia deweerdtae. The absolute configurations of the remote dimethyl-branched stereocenters in plakinic acid $\mathrm{K}$ were assigned by degradation of plakinic acid $\mathrm{K}$ to a long-chain naphthamide and analysis by liposomal circular dichroism (L-CD) and comparison with synthetic standards.
\end{abstract}

The marine sponges of the genera Plakortis and Plakinastrella ${ }^{1}$ are prolific producers of cyclic polyketide peroxides that exhibit a broad spectrum of biological properties, including antifungal ${ }^{1}$, antimalarial ${ }^{2}$, antiprotozoal- ${ }^{3}$ and immunosuppressant ${ }^{4}$ activities. Spongederived cyclic peroxides may occur as 1,2-dioxane or 1,2-dioxolane ring systems. ${ }^{5} \mathrm{We}$ recently reported the stereochemical assignments of two $\omega$-phenyl polyketide peroxides, plakinic acids I (1) and J (2) from the symbiotic two-sponge association, Plakortis halichondroidesXestospongia deweerdtae Lehnert \& van Soest, $1999,{ }^{6}$ which showed differential inhibition against haplodefficient lag $1 \Delta / \mathrm{LAG} 1$ strains of Saccharomyces cerevisiae. ${ }^{7}$ The remote methyl-branched C8 stereocenters of $\mathbf{1}$ and $\mathbf{2}$ were solved by the application of liposomal circular dichroism $(\mathrm{L}-\mathrm{CD})^{8}$ - a very sensitive technique (limit of detection $\sim 16 \mathrm{nmol}$ ) that amplifies CD Cotton effects (CEs) through ordering of the long-chain lipids in highly-uniform, unilamellar liposomes.7. Here, we show a remarkable long-range perturbation of naphthamide chromophores by a single methyl branch, over eight bonds away, that discriminates between spectroscopically indistinguishable diastereomers. L-CD was used to assign configurations of

tmolinski@ucsd.edu.

$\$$ Department of Chemistry and Biochemistry

†Skaggs School of Pharmacy and Pharmaceutical Sciences

†Present address, Department of Chemistry, University of British Columbia, Vancouver, BC, Canada V6T 1Z1. EWR.

Supporting Information Available. Full isolation and characterization of 3, 4, plakinic acid M (S1), degradation of $\mathbf{3}$ and 4, synthetic procedures, ${ }^{1} \mathrm{H}$ and ${ }^{13} \mathrm{C}$ NMR spectra of 3-23, and CD spectra of 7-9. This material is available free of charge via the Internet at http://pubs.acs.org. 
both proximal $\mathrm{C} 8$ and distal $\mathrm{C} 12$ methyl-branched centers in two new $\omega$-phenyl polyketide peroxides, plakinic acids $\mathrm{K}(\mathbf{3})$ and $\mathrm{L}(\mathbf{4})$.

$P$. halichondroides $-X$. deweerdtae, collected from the Bahamas, was extracted with $\mathrm{MeOH}: \mathrm{CH}_{2} \mathrm{Cl}_{2}$ (1:1) to yield a dark-brown residue which was sequentially extracted with $n$ hexane, chloroform, $n$-butanol and water. Antifungal bioassay-guided fractionation revealed that the $\mathrm{CHCl}_{3}$-soluble extract exhibited potent activity against $S$. cerevisiae lag $1 \Delta / \mathrm{LAG} 1$ strain. This fraction was subjected to flash chromatography (silica, $0-100 \% \mathrm{MeOH}-\mathrm{CHCl}_{3}$, stepped gradient) and the active fraction further purified by HPLC $\left(\mathrm{RP}-\mathrm{C}_{18} \mathrm{CH}_{3} \mathrm{CN} / \mathrm{H}_{2} \mathrm{O}\right)$ to yield known compounds $1,2,{ }^{7}$ new methyl-branched plakinic acids $\mathrm{K}(\mathbf{3}), \mathrm{L}(\mathbf{4})$ and plakinic acid $\mathbf{M}$, a linear homolog of $\mathbf{1} .^{9}$

Plakinic acid K (3) was isolated as an optically active colorless oil $\left(4.74 \times 10^{-3} \%\right.$ yield, w/w, wet weight), $[\alpha]_{\mathrm{D}}-137$ ( $1.31, \mathrm{CHCl}_{3}$ ) of molecular formula $\mathrm{C}_{26} \mathrm{H}_{44} \mathrm{O}_{4}$ as determined by HREIMS $\left[\mathbf{M}^{+}\right] \mathrm{m} / z, 432.3239$, with 14 mass units greater than $\mathbf{1}$. The UV, IR, ${ }^{1} \mathrm{H}$ and ${ }^{13} \mathrm{C}$ NMR spectra of $\mathbf{3}$ were almost identical to those of $\mathbf{1}$, except for an additional methyl group $\left(\delta_{\mathrm{H}} 0.82\right.$, d, $\left.J=6.4 \mathrm{~Hz} ; \delta_{\mathrm{C}} 19.9, \mathrm{CH}_{3}\right)$. Inspection of the COSY and $\mathrm{HMBC}$ spectra established the position of the second methyl branch at $\mathrm{C} 12$ (see Supporting Information). Using a similar analysis, plakinic acid $\mathrm{L}\left(\mathbf{4}, 7.5 \times 10^{-3} \%\right.$ yield w/w wet weight, $[\alpha]_{\mathrm{D}}-26.2\left(c 1.90, \mathrm{CHCl}_{3}\right)$ $\mathrm{C}_{25} \mathrm{H}_{40} \mathrm{O}_{4}$; HREIMS $\left[\mathrm{M}^{+}\right] \mathrm{m} / z$ 404.2918) was shown to be a homolog of 2.

The common origin of $\mathbf{1 - 4}$, similar specific rotations and ${ }^{1} \mathrm{H}$ NMR suggest that the respective stereocenters at C3, C4 and C6 have the same configurations as those of $\mathbf{1}$ and $2 .{ }^{10}$ The configurations of the proximal $\mathrm{C} 8 / \mathrm{C} 7$ stereocenters in $\mathbf{1}$ and $\mathbf{2}$ were assigned as $R$ by interpretation of the intense CEs in L-CD of the derived 6-methoxy-2-naphthamide (in contrast, $\mathrm{CD}$ of the naphthamides in isotropic media, such as methanol solutions, showed only baseline). ${ }^{7}$ We had proposed7 that the strong, bi-signate CEs displayed in L-CD spectra arise from pairwise intramolecular exciton coupling of naphthamides within the liposomal bilayers.

Phospholipid bilayers, comprised of saturated long chains, promote hexagonal close packing of extended $\mathrm{CH}_{2}$ groups.

The dimensions of the problem expand significantly for assignment of the remote $\mathrm{C} 12 / \mathrm{C} 11$ methyl-branched stereocenters in $\mathbf{3}$ and $\mathbf{4}$. We surmised the remote methyl branch in $\mathbf{3}$ and $\mathbf{4}$ may alter the chain packing and influence the magnitude and form of the naphthamide CEs in L-CD. This would constitute net transmission of stereochemical information from the remote C12 center to the naphthamide group, however, it was not certain the effect would be large enough to be readily observable in the $\mathrm{CD}$ spectrum.

In order to test this hypothesis, $\mathbf{3}^{11}$ was degraded (Scheme 1) by cleavage of the C6-C7 bond using $\mathrm{Fe}$ (II)-promoted reductive fragmentation $\left(\mathrm{FeCl}_{2}\right.$, aq. $\mathrm{CH}_{3} \mathrm{CN}-\mathrm{H}_{2} \mathrm{O}, \mathrm{N}_{2}$-sparged) to give primary alkyl chloride $\mathbf{5}^{12}$, which was subsequently transformed by a three-step sequence ${ }^{7}$ to give naphthamide 7.

Compound 7 was formulated into a highly-uniform, unilamellar liposomes of distearoyl-snglycero-3-phosphocholine (DSPC) as previously described, ${ }^{13}$ (phospholipid: 7 ratio $=20: 1$ ) prior to measurement of the $\mathrm{CD}$ spectrum. Remarkably, no signal appeared in the $\mathrm{CD}$ spectrum of 7 (Figure 2a) immediately after formulation in liposomes, but over 24 hours intense, complex CEs gradually appeared that were stable ( $>30$ days) and reproducible $[\lambda 196 \mathrm{~nm}(\Delta \varepsilon-11.6)$, 213 (+37.4), $226(-6.5), 255(+5.6)]$. Fitting the time-dependence of the $\mathrm{CE}$ at $\lambda=226 \mathrm{~nm}$ in L-CD spectrum of 7 (Figure 2c) to an exponential function gave $t_{1 / 2}=385$ minutes. Evidently, the kinetics of lipid chain reorganization of liposomal 7 at room temperature are considerably slower than the corresponding naphthamides derived from $\mathbf{1}$ and $\mathbf{2}$ in which less complex CEs appeared essentially immediately. ${ }^{14}$ The assignment of configuration in $\mathbf{7}$ was completed by 
comparison with synthetic model compounds $(2 S, 6 R)-\mathbf{8}$ and $(2 R, 6 R)-\mathbf{9}$ which were prepared as follows.

Tosylation of (S)-(-)-citronellol ${ }^{15} \mathbf{1 0}$ gave $\mathbf{1 1}{ }^{16}$ in $87 \%$ yield (Scheme 2), which upon treatment with lithium phenylacetylide (reflux, THF), afforded enyne $\mathbf{1 2}$ in $92 \%$ yield.

Two-step Johnson-Lemieux oxidation ${ }^{17}$ of 12 provided aldehyde 14 (Scheme 2), which was subjected to Horner-Wadsworth-Emmons olefination to give $\alpha, \beta$-unsaturated ester $\mathbf{1 5}$ as an inseparable 1:1 mixture of $E / Z$ isomers. Hydrogenation of enyne $15(\mathrm{Pd} / \mathrm{C})$ afforded saturated ester 16, which was saponified ( $\mathrm{LiOH}, \mathrm{THF} /$ water) to give acid $\mathbf{1 7}$ as a 1:1 mixture of diastereomers, epimeric at $\mathrm{C} 2$. Acid $\mathbf{1 7}$ was coupled with $(S)$-phenethylamine (HATU, $i$ $\mathrm{Pr}_{2} \mathrm{NEt}$ ) (Scheme 3$)$ to provide a mixture of diastereomeric amides $(2 S, 6 R)-\mathbf{1 8}$ and $(2 R$, $6 R)-\mathbf{1 9}$, which were separated by silica gel chromatography. ${ }^{18}$ Amides 18 and 19 were individually treated with $\mathrm{BH}_{3} \bullet$ THF to afford secondary amines $\mathbf{2 0}$ and $\mathbf{2 1}$. Hydrogenolysis of 20 and $21\left(\mathrm{Pd} / \mathrm{C}, \mathrm{CF}_{3} \mathrm{CH}_{2} \mathrm{OH}\right)$ provided primary amines $\mathbf{2 2}$ and $\mathbf{2 3}$ in $92 \%$ and $72 \%$ yield, respectively. Separate acylation of $\mathbf{2 2}$ and $\mathbf{2 3}$ (6-methoxy-2-naphthoyl chloride, $\left.\mathrm{Et}_{3} \mathrm{~N}, \mathrm{DMAP}\right)$ gave naphthamides $(2 S, 6 R)-\mathbf{8}$ and $(2 R, 6 R)-\mathbf{9}$.

Comparisons of the L-CD spectra of three stereoisomers are shown in Figure 2: 7 derived from $\mathbf{3}$ or $\mathbf{4}$, and synthetic compounds $(2 S, 6 R)-\mathbf{8}$ and $(2 R, 6 R)-\mathbf{9}$. The signs and magnitudes of the CEs are primarily dominated by perturbation of the naphthamide chromophore by the proximal stereocenter $\mathrm{C} 2$ within the first sphere of asymmetry. It is also evident that longer range perturbation from the remote methyl branch alters the forms of L-CD spectra of $(2 S, 6 R)-8$ and $(2 S, 6 S)-9)$ as a function of the $\mathrm{C} 6$ configuration (Figures $2 \mathrm{~b}$ and $\mathrm{d}$ ). Whereas the diastereomers $(2 S, 6 R)-8$ and $(2 R, 6 R)-9$ were indistinguishable by NMR, ${ }^{19}$ they were clearly differentiated by the CEs and fine structure of their L-CD spectra. In order to evaluate the effect of the distal C6 stereocenter, the L-CD of $(2 S, 6 R)-8$ was compared with the inverted L-CD of $(2 R, 6 R)-9$ (Figure 2d) which corresponds to $(2 S, 6 S)-9$. The CEs in $8\left[\lambda_{\max } 196(\Delta \varepsilon+11.0), 213(-34.0)\right.$, $226(+27.3), 258(-4.9)]$ were changed in 9 , particularly $\lambda 217 \mathrm{~nm}(\Delta \varepsilon+17.5)$ and $\lambda 256 \mathrm{~nm}$ $(\Delta \varepsilon-6.2)$ (see Table $\mathrm{S} 4$ for complete data).

The L-CD of 7 did not match either enantiomer of 9: it was equal in magnitude and form, but opposite in sign to that of $(2 S, 6 R)-\mathbf{8}$ (Figure $2 \mathrm{~b}$ ). Therefore, $\mathbf{7}$ and $(2 S, 6 R)-\mathbf{8}$ are enantiomers and the complete configurations of $\mathbf{3}$ and $\mathbf{4}$ are $3 S, 4 S, 6 R, 8 R, 12 S$ and $3 R, 5 R, 7 R, 11 S$, respectively.

Compounds 1-4 were assayed for antifungal activity against strains of Candida albicans, $C$. glabrata, C. krusei and Cryptococcus neoformans (Table 1). All compounds were exceedingly potent antifungal agents (MICs $\leq 0.5 \mu \mathrm{g} / \mathrm{mL}$ ) against all seven strains. The monomethyl-

branched $\omega$-phenyl polyketide peroxides $\mathbf{1}$ and $\mathbf{2}$ were about twice as active as plakinic acids $\mathrm{K}(3)$ and L (4). Compound 2 showed the most potent activity (MIC $<0.12 \mu \mathrm{g} / \mathrm{mL}$ ) against $C$. albicans 96-489, C. albicans UCD-FRI and C. glabrata suggesting that the 1,2-dioxolane ring and a monomethyl-branch in the $\omega$-phenylalkyl side-chain are key determinants of antifungal activity.

In conclusion, liposomal CD differentiates long-chain methyl-branched naphthamides, with epimeric configurations at a stereocenter eight bonds removed from the chromophore. Comparison of the L-CD spectrum of the naphthamide, obtained by degradation of plakinic acid K (3), with those of diastereomeric synthetic models, allowed assignment of C8/C7 and C12/C11 of plakinic acids K (3) and L (4), respectively. This remarkable long-range propagation of stereochemical information is made possible by amplification of the Cotton effects through ordering of lipid chains within the liposomal bilayer. The current work also provides CD references for interrogation of remote double methyl-branched polyketides by L- 
CD. Additional applications of L-CD are the subject of ongoing investigations in our laboratories.

\section{Supplementary Material}

Refer to Web version on PubMed Central for supplementary material.

\section{Acknowledgments}

We thank A. Marcus (University of Oregon) for helpful discussions, S. Zea (Universidad Nacional de Colombia) for identification of the sponges, and C. Green (Takasago International Corporation, U.S.A.) for a generous gift of $(S)$ (-)-citronellal. The authors are grateful to B. Morinaka and A. Jansma for assistance with NMR experiments, and J. Pawlik (University of North Carolina, Wilmington) and the crew of the RV Seward Johnson for logistics of sponge collection. EI HRMS data were provided by Y. Su. The $500 \mathrm{MHz}$ NMR spectrometers were purchased with funds from NSF (CRIF, CHE0741968). Financial support of this work was provided by the National Institutes of Health (CA1225601 and AI039987).

\section{References}

1. (a) Phillipson DW, Rinehart KL Jr. J Am Chem Soc 1983;105:7735-7736. (b) Davidson BS. J Org Chem 1991;56:6722-6724. (c) Qureshi A, Salva J, Harper MK, Faulkner DJ. J Nat Prod 1998;61:1539-1542. [PubMed: 9868160] (d) Sandler JS, Colin PL, Hooper JNA, Faulkner DJ. J Nat Prod 2002;65:1258-1261. [PubMed: 12350142]

2. Hu JF, Kelly M, Gao GF, Hamann MT. Tetrahedron 2001;57:9379-9383.

3. Perry TP, Dickerson A, Khan AA, Kondru RK, Beratan DN, Wipf P, Kelly M, Hamann MT. Tetrahedron 2001;57:1483-1487.

4. Costantino V, Fattorusso E, Mangoni A, Di Rosa M, Ianaro A. J Am Chem Soc 1997;119:1246512470.

5. Different polyketide peroxides have been found in tunicates. (a) Reyes F, Rodríguez-Acebes R, Fernández R, Bueno S, Francesch A, Cuevas C. J Nat Prod 2010;73:83-85. [PubMed: 20014800] (b) Fontana A, Gonzalez MC, Gavagnin M, Templado J, Cimino G. Tetrahedron Lett 2000;41:429-432. (c) Durán R, Zubía E, Ortega MJ, Naranjo S, Salvá J. Tetrahedron 2000;56:6031-6037.

6. While $n$ - and iso-alkyl cyclic peroxides are found in free-living P. halichondroides, we found only the $P$. halichondroides-X. deweerdtae association produces $\omega$-phenyl-terminated polyketide peroxides.

7. Dalisay DS, Quach T, Nicholas GN, Molinski TF. Angew Chem Int Ed Engl 2009;48:4367-71. [PubMed: 19437515]

8. (a) MacMillan JB, Molinski TF. J Am Chem Soc 2004;126:9944-5. [PubMed: 15303868] (b) Macmillan JB, Linington RG, Andersen RJ, Molinski TF. Angew Chem Int Ed Engl 2004;43:594651. [PubMed: 15547902]

9. See S1, Supporting Information for complete characterization.

10. The absolute configurations at stereocenters around the 1,2-dioxane ring in $\mathbf{1}$ were solved conventionally by integrated analysis of ROESY spectra and the modified Mosher's ester method. The absolute configurations of C4 and C5 within the 1,2-dioxolane ring of 2 were assigned by comparison of the $[\alpha]_{D}$ with those of synthetic 'plakinates' of defined configuration. Dai $P$, Trullinger TK, Liu X, Dussault PH. J Org Chem 2005;71:2283-92. and Ref. 7. [PubMed: 16526775]

11. Plakinic acid L (4) also gave 5 under the same conditions.

12. Compound $\mathbf{5}$ arises from C6-C7 bond scission initiated by a 'chloro-Fenton' reaction that captures $\mathrm{Cl}$ from the Fe ligand sphere by radical rebound. Ref. ${ }^{7}$ and Sawyer DT, Hage JP, Sobkowiak A. J Am Chem Soc 1995;117:106-9.

13. The crude liposome suspension, prepared by shell-evaporation of a solution of naphthamides and DSPC in $\mathrm{CHCl}_{3}(2 \mathrm{mg} / \mathrm{mL})$, followed by sonication in water and thermal annealing, was repeatedly extruded under pressure through a $100 \mathrm{~nm}$ pore polycarbonate membrane to give uniform diameter, unilamellar liposomes. Ref. ${ }^{8}$. 
14. The higher-order complexity of L-CD spectrum of 7 (which is the subject of our ongoing investigations) is indicative of delocalized intermolecular excitons, or J-arrays. Fidder H, Knoester J, Wiersma DA. J Chem Phys 1993;98:6564-66.

15. (-)-Citronellol (10) obtained from TCI-EP [lot GM01] was of low optical purity $\left(72 \%\right.$ ee, $[\alpha]_{\mathrm{D}}{ }^{20}$ -3.42 (neat); lit. $[\alpha]_{\mathrm{D}}{ }^{20}-4.76^{\circ}$ (neat) Rienäcker R, Ohloff G. Angew Chem 1961;73:240.).

Consequently, pure (-)-10 $\left(98 \%\right.$ ee, $[\alpha]_{\mathrm{D}}{ }^{20}-5.18$ (neat)) was obtained by reduction $\left(\mathrm{NaBH}_{4}\right.$, $\mathrm{MeOH}$ ), of (-)-citronellal (Takasago, 98\%ee).

16. Mori K, Masuda S, Suguro T. Tetrahedron 1981;37:1329-1340.

17. Pappo R, Allen DS Jr, Lemieux RU, Johnson WS. J Org Chem 1956;21:478-9.

18. The assignment of the $\mathrm{C} 2$ configurations in $\mathbf{1 8}$ and $\mathbf{1 9}$ followed from ${ }^{1} \mathrm{H}$ NMR comparisons with analogs of known configuration. Nicholas GM, Molinski TF. Tetrahedron 2000;56:2921-27.

19. ${ }^{13} \mathrm{C} \mathrm{NMR}\left(\mathrm{CDCl}_{3}, 125 \mathrm{MHz}\right): \Sigma[\Delta \delta(\mathbf{8}-\mathbf{9})]^{2}<0.07 \mathrm{ppm}$. 
<smiles>CCCCC[C@@H](C)C[C@]1(C)C[C@@H](C)[C@@H](CC(=O)O)OO1</smiles>
1<smiles>CC(C)CC(C)(C)c1ccccc1</smiles><smiles>C[C@@H](CCC[C@@H](C)Cc1ccccc1)C[C@]1(C)C[C@@H](C)[C@@H](CC(=O)O)OO1</smiles>

Figure 1.

Structures of plakinic acids I (1), J (2), K (3) and L (4).<smiles>CC(C)C[C@H](C)C[C@]1(C)C[C@@](C)(CC(=O)O)OO1</smiles>

2

4<smiles>CC(C)C[C@]1(C)C[C@@](C)(CC(=O)O)OO1</smiles> 


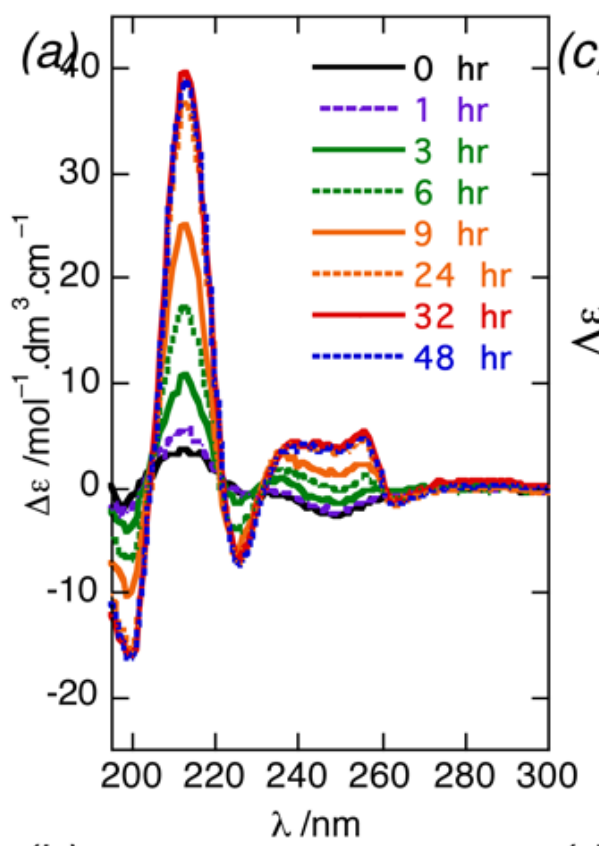

(b)
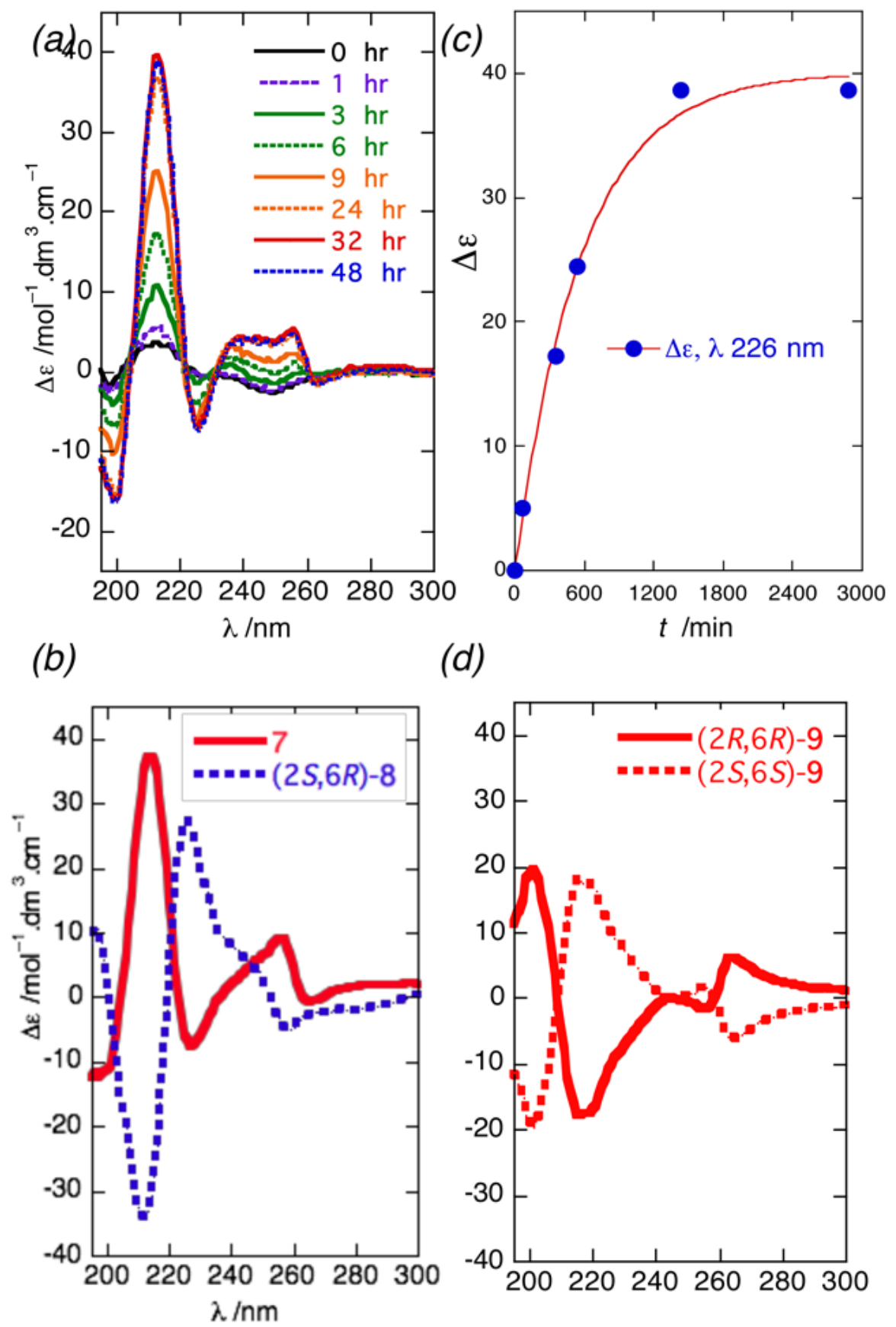

Figure 2.

Liposomal circular dichroism (L-CD) spectra $\left(T=23^{\circ} \mathrm{C}\right.$ ). (a) 7 from $t=0$ to $48 \mathrm{hrs}$ after formulation of liposomes $\left(\mathrm{H}_{2} \mathrm{O}\right.$, diastearoyl-sn-3-glycero-phosphocholine, $2 \mathrm{mg} / \mathrm{mL}$; mole ratio of phospholipid:7 $=20: 1)$. (b) 7, $c=2.24 \times 10^{-4} \mathrm{M}$ and $(2 S, 6 R)-8, c=2.25 \times 10^{-4} \mathrm{M}$. (c) Time-dependence of the Cotton effect of $7(\lambda=226 \mathrm{~nm})$, post-formulation. (d) $(2 R, 6 R)-\mathbf{9}, c=$ $2.47 \times 10^{-4} \mathrm{M}$ and ent-9 (calculated). 
<smiles>CC(CCC[C@@H](C)CCl)CC(C)c1ccccc1</smiles>
rt, 45 min

5<smiles>C[C@@H](CCC[C@@H](C)CN)CN(C)c1ccccc1</smiles>

$$
\begin{aligned}
& \text { i. } \mathrm{H}_{2}, \mathrm{Pd}-\mathrm{C} \\
& \text { hexane/EtOH }
\end{aligned}
$$

6

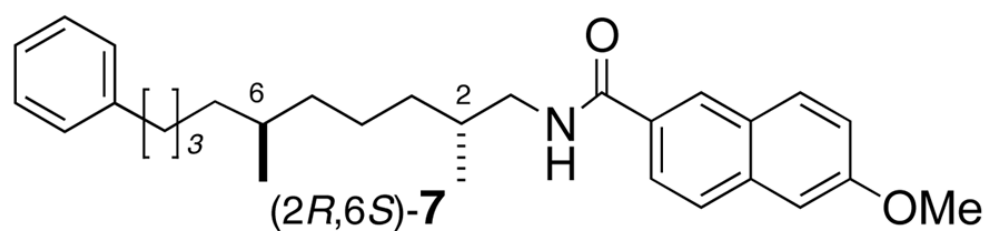<smiles>COc1ccc2cc(C(=O)NCC(C)CCC[C@@H](CC(C)C)CC(C)(C)c3ccccc3)ccc2c1</smiles>

$\mathrm{OMe}$

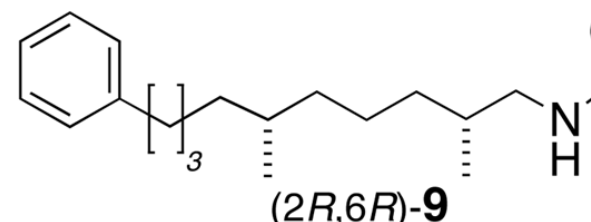<smiles>COc1ccc2cc(C(=O)I)ccc2c1</smiles>

Scheme 1.

Degradation of $\mathbf{3}$ and conversion to $\mathbf{7}$ 


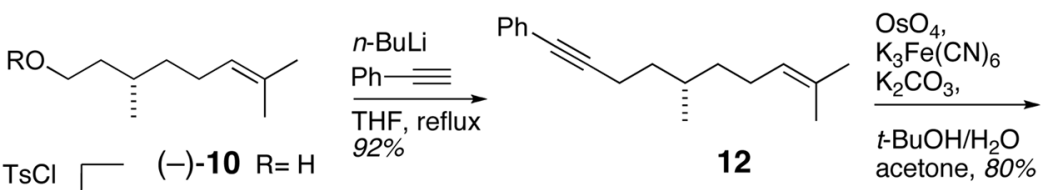

$\underset{87 \%}{\text { pyrid, }} \longrightarrow 11 \mathrm{R}=\mathrm{Ts}$

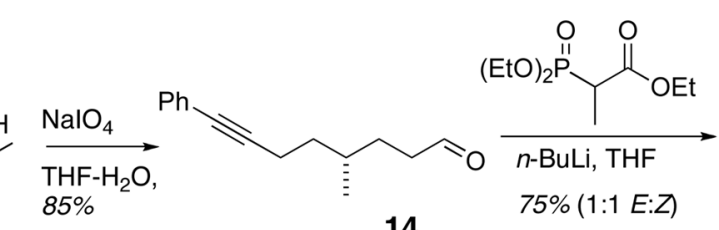

13

14
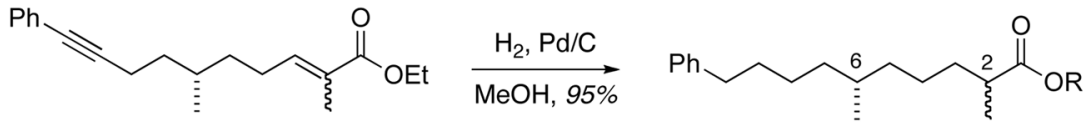

$15 E, Z$

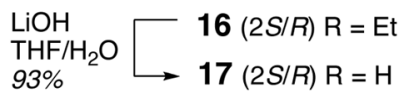

Scheme 2.

Synthesis of an epimeric mixture of acids $\mathbf{1 7 .}$ 
<smiles>CC(CCCC(C)C(=O)Cl)Cc1ccccc1</smiles>

17

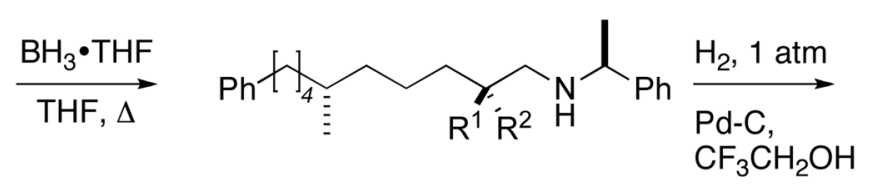

(2S,6R)-20 $\mathrm{R}^{1}=\mathrm{Me}, \mathrm{R}^{2}=\mathrm{H}, 90 \%$

$(2 R, 6 R)-21 R^{1}=H, R^{2}=\mathrm{Me}, \quad 72 \%$

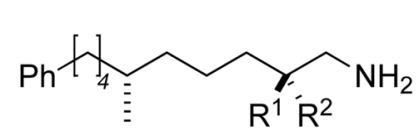

$(2 S, 6 R)-22 \mathrm{R}^{1}=\mathrm{Me}, \mathrm{R}^{2}=\mathrm{H}, 92 \%$

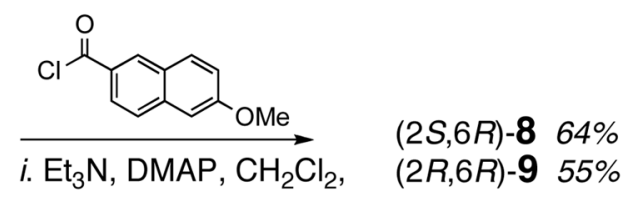

$(2 R, 6 R)-23 \mathrm{R}^{1}=\mathrm{H}, \mathrm{R}^{2}=\mathrm{Me}, 72 \%$ ii. quench, $\mathrm{Me}_{2} \mathrm{~N}\left(\mathrm{CH}_{2}\right)_{3} \mathrm{NH}_{2}$

Scheme 3.

Synthesis of standards, naphthamides $\mathbf{8}$ and $\mathbf{9}$. 


\section{Table 1}

Antifungal activities of plakinic acids I-L (1-4). Minimum inhibitory concentration, MIC $(\mu \mathrm{g} / \mathrm{mL})^{a}$.

\begin{tabular}{lcccc}
\hline & $\mathbf{1}$ & $\mathbf{2}$ & $\mathbf{3}$ & $\mathbf{4}$ \\
\hline C. albicans, ATCC 14503 & 0.25 & 0.25 & 0.50 & 0.50 \\
C. albicans $96-489$ b & 0.06 & $<0.03$ & 0.12 & 0.12 \\
C. albicans UCD-FR1 ${ }^{b}$ & 0.25 & 0.12 & 0.50 & 0.50 \\
C. glabrata & 0.12 & 0.06 & 0.12 & 0.12 \\
C. krusei & 0.06 & 0.12 & 0.12 & 0.12 \\
Cryptococcus neoformans var. gattii & 0.12 & 0.25 & 0.12 & 0.50 \\
C. neoformans var. grubii & 0.12 & 0.25 & 0.12 & 0.50 \\
\hline
\end{tabular}

${ }^{a}$ The in vitro susceptibilities were determined by the microbroth dilution method according to the guidelines of the National Committee for Clinical Laboratory Standards (NCCLS)

${ }^{b}$ Fluconazole-resistant $(\mathrm{MIC}>64(\mu \mathrm{g} / \mathrm{mL})$. 